УДК 368.9 JEL G22

DOI: $10.17223 / 22229388 / 26 / 1$

\section{А.К. Сембеков}

\section{ОРГАНИЗАЦИЯ ЗАЩИТЫ ИНТЕРЕСОВ СТРАХОВАТЕЛЕЙ - ПОТРЕБИТЕЛЕЙ УСЛУГ НА КАЗАХСТАНСКОМ СТРАХОВОМ РЫНКЕ}

Статья посвящена организации системы защиты интересов потребителей страховых услуг в Казахстане. Рассматриваются особенности организации защиты интересов потребителей страховых услуг на макро- $u$ микроуровнях. В проиессе исследования были выявлены проблемы в реализачии защчиты интересов страховых услуг на казахстанском страховом рынке.

Ключевые слова: защчита интересов потребителей страховых услуг, страхователи, страховые услуги, финансовая устойчивость, платежеспособность.

Формирование полноценной системы защиты интересов страхователей в Казахстане началось с возникновением рыночных отношений на страховом рынке и возрастающей конкуренции страховых компаний в борьбе за клиента - потенциального потребителя финансовых услуг. Организация защиты интересов страховых услуг стала играть значительную роль в функционировании страхового рынка, ибо аккумулируемые значительные денежные ресурсы должны быть базисом реального обеспечения имущественных интересов страхователей в обеспечении страховых выплат, обоснованных наступлением страхового случая и нанесением ущерба потребителю услуг.
Одной из основных причин серьезных нарушений прав потребителей страховых услуг может стать вероятность появления на рынке финансово неустойчивых компаний, что приводит к возникновению проблем с обеспечением платежеспособности страховщика.

Реализация защиты интересов потребителей в сфере страховых услуг возможно осуществлять как на макро-, так и на микроэкономическом уровнях (таблица).

На макроэкономическом уровне формируется основной механизм защиты интересов потребителей страховых услуг, который возлагается государством на орган национального страхового надзора, в данном случае на Национальный банк Республики Казахстан. Надзорный орган для своевременного выявления финансовой несостоятельности страхового общества и принятия мер для его оздоровления или защиты интересов страхователей законодательно установил нормативы пруденциальных требований, в том числе по размерам собственного капитала, минимального уровня маржи платежеспособности и гарантийного фонда страховых организаций. Минимальный уровень собственного капитала, маржи платежеспособности и гарантийного фонда устанавливается нормативными инструкциями надзорного органа. Также в целях недопущения ухудшения финансового положения страховых компаний в процессе страховой деятельности надзорный орган Республики Казахстан установил контроль за административно-управленческими расходами (не выше 40 \%) компании. Все страховые организации, осуществляющие страховую деятельность на территории республики, обязаны ежемесячно предоставлять финансовую отчетность о своей деятельности, включая бухгалтерский баланс, отчет доходов и убытков, отчет о движении денег, отчет о выполнении пруденциальных нормативов и др.

Уровни защиты интересов потребителей страховых услуг

\begin{tabular}{|l|l|l|}
\hline \multicolumn{1}{|c|}{ Уровень } & Инфраструктурные институты & \multicolumn{1}{|c|}{ Механизм защиты } \\
\hline $\begin{array}{l}\text { Микроэко- } \\
\text { номический }\end{array}$ & Страховые компании & $\begin{array}{l}\text { Собственный капитал. } \\
\text { Страховые резервы. } \\
\text { Перестрахование }\end{array}$ \\
\hline $\begin{array}{l}\text { Макроэко- } \\
\text { номический }\end{array}$ & Государство & $\begin{array}{l}\text { Нормативно-правовые акты. } \\
\text { Инспекционный и дистанционный надзор. } \\
\text { Фонд гарантирования страховых выплат }\end{array}$ \\
\hline
\end{tabular}

Как принято в мировой практике страхования, в числе задач регулирования страхового рынка определены основные функции страхового надзора Республики Казахстан (ст. 43 Закона РК «О страховой деятельности») в части организации надзора за страховой деятельностью и защитой интересов потребителей. Права органа страхового надзора Казахстана соответствуют опыту мировой практики, в частности, получать отчетность по страховой деятельности, проводить проверки соблюдения страхово- го законодательства, давать предписания страховым компаниям и др.

Орган страхового надзора по отношению к страховым организациям вправе отозвать лицензии по определенным видам страховых операций либо приостановить деятельность страховой компании на срок до 6 мес в случае невыполнения предписаний об устранении выявленных нарушений законодательства, несоблюдения минимальных условий финансовой устойчивости и других нарушений. 
В казахстанской страховой практике надзор за платежеспособностью и финансовой устойчивостью страховых организаций осуществляется посредством установления для них пруденциальных нормативов и иных обязательных к соблюдению норм и лимитов (ст. 46 Закона Республики Казахстан «О страховой деятельности»). Для страховой компании устанавливаются законодательным путем пруденциальные нормативы, характеризующие уровень соответствия платежеспособности, гарантийного фонда, ликвидности активов страховщика и др.

К пруденциальным нормативам страховой компании, установленным постановлением уполномоченного органа, относятся:

1) минимальный размер уставного капитала;

2) норматив достаточности маржи платежеспособности;

3) норматив достаточности высоколиквидных активов;

4) нормативы диверсификации активов.

Орган надзора вправе устанавливать дополнительные пруденциальные нормативы. Гарантийный фонд создается в целях обеспечения финансовой устойчивости и платежеспособности страховщика в результате снижения маржи платежеспособности ниже минимально установленного уровня.
В целях защиты интересов страхователей в законодательном порядке установлена ответственность по обязательствам перед страхователями обанкротившихся страховых организаций. Для этого по опыту многих стран в Республике Казахстан создан специальный гарантийный фонд - так называемый Фонд гарантирования страховых выплат (ФГСВ). Основным источником финансовых ресурсов для покрытия обязательств обанкротившихся страховых организаций являются отчисления, поступающие от специальных сборов на эти цели со страховых организаций по обязательным видам страхования. Это подтверждает и мировой опыт. Минимальный размер гарантии интересов страхователей со стороны государства по обязательным видам страхования определен с учетом интересов всех заинтересованных сторон.

Фонд гарантирования страховых выплат (ФГСВ) гарантирует 3 класса обязательного страхования:

- ГПО владельцев транспортных средств;

- ГПО перевозчика перед пассажирами;

- ГПО туроператора и турагента.

Рассмотрим основные финансовые показатели страховых организаций участников Фонда гарантирования страховых выплат Республики Казахстан (рис. 1).

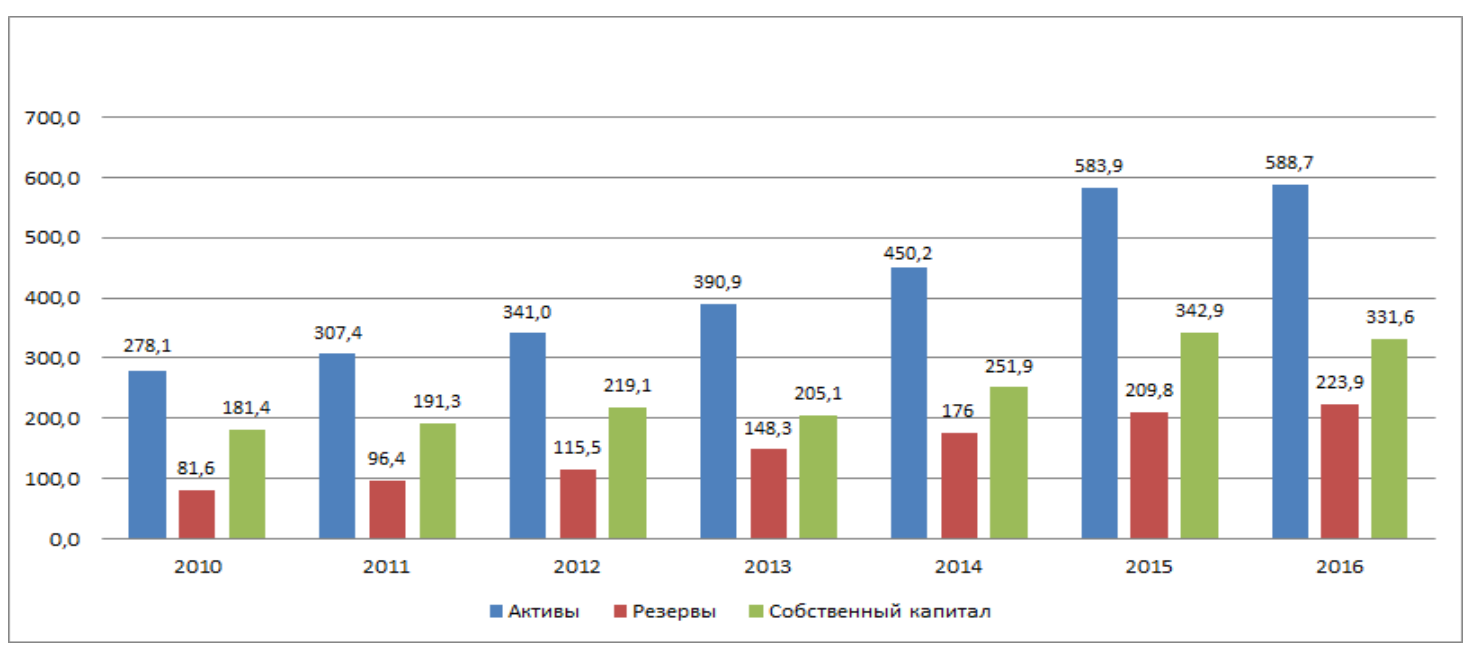

Рис. 1. Активы, резервы и собственный капитал страховых организаций, входящих в систему гарантирования страховых выплат, млрд тенге

В 2015 г. количество страховых организаций членов фонда гарантирования страховых выплат составляло 30 компаний, а в 2016-2017 гг. произошло снижение количества компаний на 8.

Рассмотрим систему защиты интересов страхователей, осуществляемую на микроэкономическом уровне. Для страховой компании важным является ее способность выполнять свои обязательства по договорам страхования, заключенным с клиентами. Риск наступления страхового случая и необходимости обеспечения выплаты страхового возмещения всегда существует. Размеры сумм страховых возмещений конкретно не могут быть определены - они могут быть достаточно большими для нанесения убытков страховой компании. Соответственно финансовая способность страховых компаний отвечать по обязательствам в любое время является необходимым условием, т.е. страховые компании должны обладать финансовой устойчивостью по выполнению своих обязательств.

Одним из значимых факторов обеспечения защиты интересов страховых услуг является обеспечение платежеспособности страховой ком- 
ОРГАНИЗАЦИЯ ЗАЩИТЫ ИНТЕРЕСОВ СТРАХОВАТЕЛЕЙ -

пании. Проведение анализа платежеспособности страховой компании является одним из первоначальных этапов присвоения рейтинговой оценки независимыми экспертами. Учитывая, что показатели платежеспособности выражают уровень доверия и надежности страховой организации для потребителей, в Великобритании (1946 г.) впервые была разработана концепция, основанная на расчете маржи платежеспособности. Метод Solvency I является простой и понятной системой, к тому же позволяющей сравнивать результаты разных компаний. Вместе с тем на практике выявились следующие недостатки:

- оценка активов и обязательств не основана на рыночных принципах;

- используемые величины - премии и выплаты в страховании «нежизни», математические резервы и капитал под риском в страховании жизни - не вполне подходят для корректной оценки андеррайтингового риска;

- остальные риски не учитываются или учитываются лишь отчасти. Так, нормативная маржа платежеспособности не включает инвестиционный риск, который покрывается отдельными указаниями;

- не принимаются во внимание диверсификация рисков, определенные формы передачи рисков, зависимости между активами и обязательствами;

- учет перестрахования ограничен, передача рисков учитывается недостаточно, как и кредитоспособность перестраховщика [1. С. 40].

Мировой финансовый кризис, наступивший с 2008 г. вследствие перегрева кредитного рынка и разразившегося ипотечного «бума», отразился в первую очередь не только на банковском секторе, но и стал отправной точкой для ускоренного внедрения новых требований к платежеспособности.

Необходимость внедрения новых стандартов платежеспособности Solvency II согласно меморандуму Европейской комиссии заключалась в том, что ранее действовавшие требования устарели, так как они не были чувствительны к рискам.

Директива Solvency II была принята в ноябре 2009 г. Европейским советом и парламентом. Однако в 2013 г. было принято решение отложить вступление в действие Solvency II до 2016 г. из-за неспособности европейских страховых компаний привести свою деятельность в соответствие с новыми требованиями в довольно сжатые сроки.

Основная идея согласно новым требованиям платежеспособности состоит в том, что страховая компания может идти на риск в случае, если у нее имеется достаточный капитал для его покрытия. Определение этого минимально необходимого капитала зависит от уровня риска и времени. Особенно важными являются идентификация и дифференциация рисков, расчет их прогнозных оценок.
Метод Solvency II включает три основополагающих принципа:

- принцип I: количественные требования к капиталу;

- принцип II: управление и надзор за деятельностью страховых финансовых институтов;

- принцип III: раскрытие информации и прозрачность их деятельности.

В рамках Solvency II страховые организации должны предоставлять регулятору результаты стресс-тестирования, по которому данная норма действует в рамках системы управления рисками, т.е. надзорным органом утверждены формы стресс-тестов, которые страховые организации ежеквартально проводят и предоставляют регулятору. На основе данных стресс-тестов регулятор имеет возможность оценить уровень устойчивости страховщика и применять превентивные меры к компаниям с низкими показателями достаточности капитала и другими регулируемыми показателями. Стресс-тестирование позволяет оценить финансовую устойчивость страховой компании и сохранить платежеспособность при негативных рыночных тенденциях [2. С. 34].

Следует отметить, что переход к системе Solvency II позволит повысить уровень защиты интересов страхователей в новых условиях.

Дальнейшее совершенствование системы защиты интересов потребителей финансовых услуг связано с образованием в 2013 г. отдела контроля финансовых организаций и защиты прав потребителей финансовых услуг в структуре Национального банка Республики Казахстан.

Основными направлениями деятельности отдела являются:

- рассмотрение обращений физических и юридических лиц по вопросам предоставления финансовых услуг, а также по вопросам инвестирования средств в финансовые инструменты;

- проведение разъяснительных работ по вопросам оказания / потребления финансовых услуг, а также защиты прав потребителей данных услуг;

- проведение работ по распространению информационных материалов, направленных на повышение финансовой грамотности потребителей финансовых услуг;

- проведение внеплановых и документальных проверок деятельности субъектов финансового рынка организаций по соблюдению законодательно установленных требований при оказании услуг и раскрытии информации об услугах по поступившим обращениям физических и юридических лиц;

- обеспечение надлежащего уровня защиты прав и законных интересов потребителей финансовых услуг [3].

Следует отметить, что до 2007 г. наблюдался рост обращений по страховому сектору. Их доля доходила до $35 \%$ от общего количества обращений. Они касались преимущественно вопросов обя- 
зательного страхования гражданско-правовой ответственности (ГПО) владельцев транспортных средств, способствовавших недобросовестной деятельности страховых организаций, и оценщиков.

Соответствующие поправки и изменения были внесены в страховое законодательство, был учрежден независимый институт страхового омбудсмана. В результате этих мер общее количество обращений в адрес страхового сектора сократилось и сейчас показатель не превышает 4 \% от общего числа обращений. А преобладающее большинство жалоб связано с добровольными видами страхования [4].

В декабре 2015 года по результатам рассмотрения обращений НБРК и его территориальными филиалами за нарушения требований законодательства Республики Казахстан и / или условий договоров применено 5 ограниченных мер воздействия, в том числе к БВУ - 3, страховой (перестраховочной) организации - 1 , микрофинансовой организации - 1 .

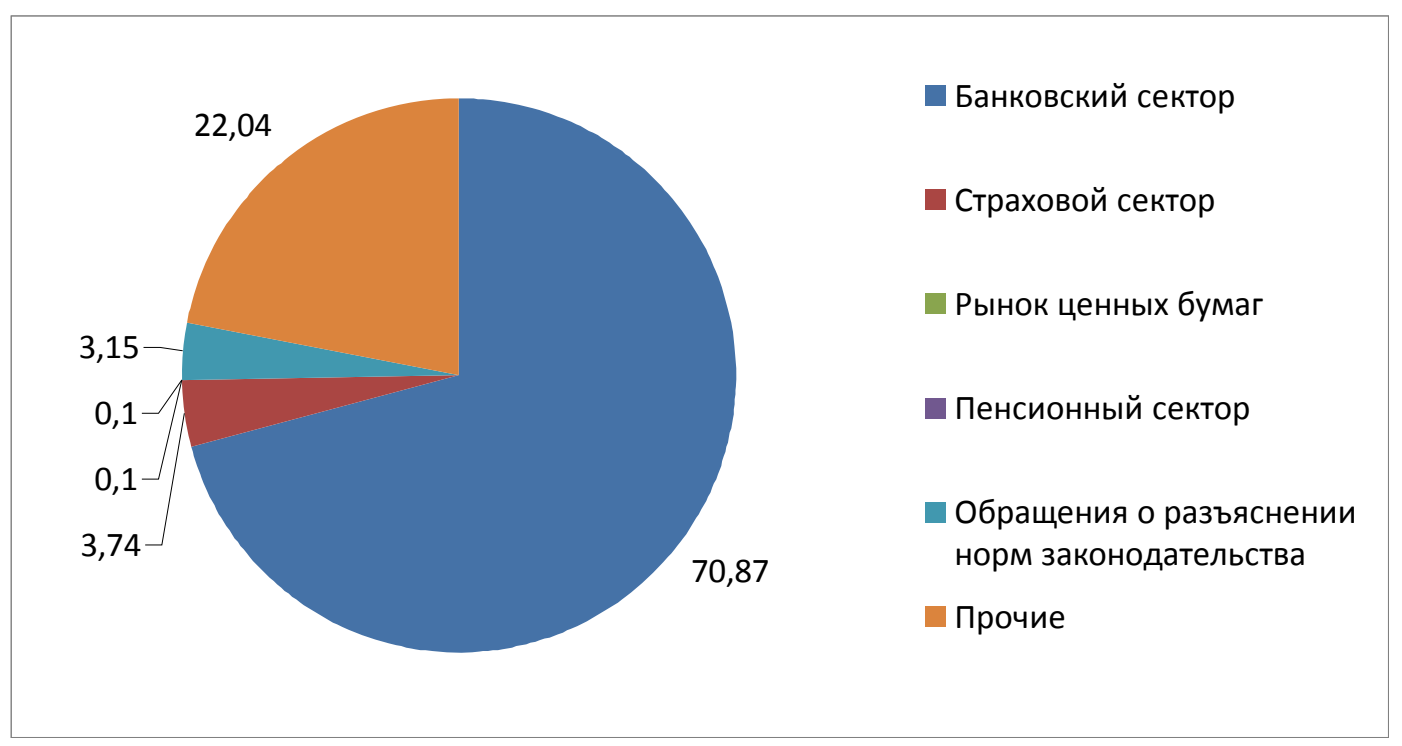

Рис. 2. Доля рассмотренных обращений по защите прав потребителей финансовых услуг Национальным банком РК

Как видно из рис. 2, наибольшая доля обращений приходится на банковский сектор - 70,87 \%. Как было сказано выше, доля обращений по страховому сектору не превышает $4 \%$.

Важным элементом в деле защиты потребителей стала деятельность саморегулируемой профессиональной организации в области защиты интересов страхователей в лице Ассоциации потребителей страховых услуг Казахстана. Согласно уставу основной целью Ассоциации является улучшение положения потребителя на рынке страхования и развитие качества страховой услуги.

Ассоциация потребителей страховых услуг Казахстана способствует:

- улучшению положения потребителя страховых услуг на рынке страхования;

- консолидации информации о деятельности страховых компаний и отзывов потребителей;

- аккредитации и оценке деятельности страховых компаний с точки зрения потребителя;

- улучшению законодательства в сфере страхования;

- консультирует клиентов, оптимизируя их расходы на страхование [5].
Несмотря на реализацию определенной системы по защите интересов страховых услуг существуют следующие нерешенные проблемы:

- система защиты направлена на обеспечение гарантии страховой выплаты, в то время как в развитых странах обращают внимание на качество страховой услуги;

- зачастую страховщики пренебрегают гарантией страховой защиты страхователей, а именно снижением размера страховой выплаты до незначительно уровня в целях достижения экономической выгоды;

- в рамках системы гарантий защиты интересов страхователей в Казахстане функционирует ограниченное число участников, в основном это страховщик и государственные структуры (Национальный банк, Фонд гарантирования страховых выплат), в то время как во многих странах активными участниками являются саморегулируемые организации, рейтинговые агентства. К примеру, в Российской Федерации свою деятельность осуществляет Межрегиональный союз защиты прав страхователей. Следует отметить, что нарушения прав страхователей в развитых странах активно освещаются в СМИ [6]. 
ОРГАНИЗАЦИЯ ЗАЩИТЫ ИНТЕРЕСОВ СТРАХОВАТЕЛЕЙ -

Нормативно-правовая база в Казахстане имеет законодательные акты в области защиты интересов потребителей услуг исключительно торговой сферы, а не финансовой.

Следующей проблемой является низкий уровень страховой культуры, страхователь зачастую не осознает свои права и обязанности, для этого он должен понимать сущность страховых отношений, иметь общее представление о деятельности страховой компании, правилах страхования, нормативно-правовой базы.

\section{Литература}

1. Котлобовский И.Б. Рисковый подход к оценке платежеспособности страховой компании / И.Б. Котлобовский, А.Е. Сметанин // Финансы. 2007. № 6.
2. Ашимова A.T. Проблемы внедрения стандарта оценки страховых рисков Solvency II в Казахстане // Банки Казахстана. 2015. № 02 (212).

3. Официальный сайт Национального банка Республики Казахстан. Режим доступа: http://nationalbank.kz/ ?\&switch=russian

4. В Национальном банке разрабатывается проект Программы по повышению финансовой грамотности казахстанцев // http://www.kba.kz/rus/news/Specproekt_Nacionaljnij_ Bank_informiruet_kommentiruet_razyjasnjaet.html

5. Официальный сайт Ассоциации потребителей страховых услуг: http://apsu.kz/234-prognozy-rynkastrahovaniia. html

6. Орланюк-Малиикая Л.А. Проблемы формирования гарантий защиты интересов потребителей страховых услуг // Вестник финансового университета. 2012. № 3. С. 66-68. 